\title{
A atuação do enfermeiro residente junto à pandemia de Covid-19: Revelando
}

\section{vivências e saberes}

\author{
The role of the resident nurse in the Covid-19 pandemics: Unveiling experiences and knowledge \\ La actuación del enfermero residente junto a la pandemia de Covid-19: Revelando vivencias y
}

saberes

Recebido: 30/03/2021 | Revisado: 09/04/2021 | Aceito: 22/04/2021 | Publicado: 08/05/2021

\author{
Suélen Larissa Oliveira de Menezes \\ ORCID: https://orcid.org/0000-0001-6960-0002 \\ Universidade Federal do Estado do Rio de Janeiro, Brasil \\ E-mail: suelenolyver@gmail.com \\ Thaiane Hermógenes Olimpio de Jezus \\ ORCID: https://orcid.org/0000-0002-0117-2993 \\ Universidade Federal do Estado do Rio de Janeiro, Brasil \\ E-mail: thaiane.hoj@gmail.com \\ Gicélia Lombardo Pereira \\ ORCID: https://orcid.org/0000-0002-4032-2093 \\ Universidade Federal do Estado do Rio de Janeiro, Brasil \\ E-mail: gicelia.pereira@unirio.br \\ Andréia Jorge da Costa \\ ORCID: https://orcid.org/0000-0001-6923-4401 \\ Universidade do Estado do Rio de Janeiro, Brasil \\ E-mail: andreiajcosta@msn.com \\ Vinícius Rodrigues de Souza \\ ORCID: https://orcid.org/0000-0001-8035-3647 \\ Escola de Saúde da Marinha, Brasil \\ E-mail: viniciussouza.enf@gmail.com \\ Geilsa Soraya Valente \\ ORCID: https://orcid.org/0000-0002-0719-638X \\ Universidade Federal Fluminense, Brasil \\ E-mail: geilsavalente@gmail.com
}

\begin{abstract}
Resumo
O artigo objetiva conhecer as vivências e saberes relatados pelo Enfermeiro Residente (ER) na atuação de pandemia de Covid-19. Trata-se de uma pesquisa social exploratória, descritiva, com abordagem qualitativa. Os dados foram coletados no período de novembro e dezembro de 2020, individualmente através de um questionário virtual com perguntas abertas e fechadas, das quais foram gerados dados objetivos e subjetivos, como valores, atitudes e opiniões. A pesquisa foi desenvolvida de acordo com as normas da Resolução 466/2012. O cenário de pandemia nas unidades de treinamento em serviço provocaram modificações no contexto prático e teórico da residência de enfermagem, pois os relatos variaram desde informações adicionais acerca da Covid-19 a sentimentos enfrentados por estes profissionais bem como sugestões de estratégias de melhoria no ensino. O desgaste psicológico dos ER foi uma interferência bastante presente no cotidiano dos entrevistados. Além disso, a pandemia despertou nos alunos a importância do uso dos EPI's durante a prestação da assistência de enfermagem. Favoreceu a inserção de avanços tecnológicos para manutenção das aulas teóricas preconizadas pelo curso. Com a pandemia, os residentes sentiram alguma lacuna em seus aprendizados decorrentes de adaptações voltadas a encontros on-line, adaptação de escala, campos de treinamento prático e oportunização de vivências de outras patologias. Desse modo, sugestões de aperfeiçoamento do curso foram elencadas: treinamentos sobre Covid-19; reavaliação das temáticas das aulas teóricas de modo que atendam a natureza de suas atividades no campo prático e apoio psicológico durante o desenvolvimento do curso.
\end{abstract}

Palavras-chave: Enfermagem; Aprendizagem; Treinamento em serviço; Pandemias; Covid-19.

\begin{abstract}
The article aims to understand the experiences and knowledge reported by the Resident Nurse (RN) in the performance of the Covid-19 pandemic. This is an exploratory, descriptive social research, with a qualitative approach. This data was collected in November and December 2020, individually through a virtual questionnaire with open and closed questions, from which both objective and subjective data were generated, such as values, attitudes and opinions. The research was developed in accordance with the norms of Resolution 466/2012. The pandemic scenario in the in-service training units caused changes in the practical and theoretical context of the nursing residency, as the reports ranged from additional information about the Covid-19 to feelings faced by these
\end{abstract}


professionals as well as suggestions for improving teaching strategies. The psychological damage of the ER was an interference very present in the daily lives of the interviewees. In addition, the pandemic has awakened in students the importance of using PPE's during the provision of nursing care. It favored the insertion of technological advances to maintain the theoretical classes recommended by the course. With the pandemic, residents felt some gap in their learning resulting from adaptations aimed at online meetings, scale adaptation, practical training fields and opportunities for experiences of other pathologies. Thus, suggestions for improving the course were listed: training on Covid-19; reassessment of the themes of the theoretical classes so that they meet the nature of their activities in the practical field and psychological support during the development of the course.

Keywords: Nursing; Learning; In-service training; Pandemics; Covid-19.

\section{Resumen}

El estudio tiene por objetivo conocer las experiencias y conocimientos reportados por el Enfermero Residente (ER) en la actuación de la pandemia Covid-19. Se trata de una investigación social exploratoria, descriptiva, con enfoque cualitativo. Los datos se recolectaron entre noviembre y diciembre de 2020, de manera individual a través de un cuestionario virtual con preguntas abiertas y cerradas, donde se generaron datos objetivos y subjetivos, como valores, actitudes y opiniones. La investigación se desarrolló de acuerdo con las normas de la Resolución 466/2012. El escenario de la pandemia en las unidades de formación en servicio provocó cambios en el contexto práctico y teórico de la residencia de enfermería, porque los reportes variaron desde información adicional sobre el Covid-19 hasta sentimientos que enfrentan estos profesionales así como sugerencias de estrategias de mejora en la enseñanza. El desgaste psicológico de los enfermeros residentes fue una interferencia muy presente en el cuotidiano de los entrevistados. Además, la pandemia ha despertado en los estudiantes la importancia de usar PPE durante la prestación de cuidados de enfermería. Favoreció la inserción de avances tecnológicos para la manutención de las clases teóricas recomendadas por el curso. Con la pandemia, los residentes sintieron cierta brecha en su aprendizaje debido a las adaptaciones dirigidas a encuentros en línea, adaptación de escalas, campos de entrenamiento práctico y oportunidades de vivencias de otras patologías. Así, se enumeraron sugerencias para mejorar el curso: capacitación sobre Covid-19; reevaluación de los temas de las clases teóricas para que respondan a la naturaleza de sus actividades en el campo práctico y apoyo psicológico durante el desarrollo del curso.

Palabras clave: Enfermería; Aprendizaje; Entrenamiento en servicio; Pandemias; Covid-19.

\section{Introdução}

Este estudo tem como objeto as vivências e saberes relatados pelo Enfermeiro Residente (ER) junto à pandemia de Covid-19. Diante das circunstâncias geradas pela disseminação desta nova enfermidade, elaborou-se a seguinte questão norteadora: quais são as vivências e os saberes dos ER que atuam na pandemia de Covid-19, possuem sobre esta pandemia? Deste modo o objetivo da pesquisa foi conhecer as vivências e saberes relatados pelo Enfermeiro Residente (ER) na atuação de pandemia de Covid-19.

Neste sentido, tornou-se relevante compreender a importância do Curso de Pós-Graduação em Nível de Especialização, sob a Forma de Treinamento em Serviço para Enfermeiros, nos Moldes de Residência na formação do enfermeiro para a qualificação e o aprimoramento profissional junto ao cenário de saúde e epidemiológico do país.

A Residência em Área Profissional de Saúde é respaldada pelo Decreto n¹1.129/2005, que define como modalidade de ensino de pós-graduação lato sensu, voltada para a educação em serviço e destinada às categorias profissionais que integram a área de saúde. Trata-se de um curso para favorecer a formação qualificada dos Enfermeiros Residentes em regime de dedicação exclusiva e sob a supervisão docente-assistencial de responsabilidade conjunta do setor de educação e saúde das Unidades de Treinamento em Serviço (UTS) (Brasil, 2005a).

Esse tipo de qualificação permite que o enfermeiro residente desenvolva o pensamento crítico-reflexivo sobre suas condutas, pois além de proporcionar o amadurecimento profissional e promover habilidades técnico-científicas, trará assistência de qualidade com segurança ao paciente. Este tipo de pós-graduação favorece a inserção destes profissionais ao mercado de trabalho (Carvalho et al., 2019).

Quanto à duração e carga horária dos Programas de Residência em Área Profissional de Saúde, a Resolução No 05 de 07/11/2014, refere que, na modalidade multiprofissional e uniprofissional, sejam desenvolvidas com $80 \%$ de carga horária total sob forma de atividades práticas e com $20 \%$ sob a forma de atividades teórico-práticas. Sendo assim totalizado com duração 
mínima de dois anos, equivalente a uma carga horária mínima total de 5.760 horas (Brasil, 2014).

Sabendo que o planejamento curricular nos moldes de residência é criterioso segundo as diretrizes pedagógicas, as universidades e o corpo docente devem reunir esforços diários no preparo/ensino de qualidade destes profissionais nos mais diversos cenários epidemiológicos do SUS.

Recentemente os hospitais de diversos países têm passado por situação caótica, com a pandemia de Covid-19 Coronavírus (Cov) - que é composto por uma grande família de vírus e que pode originar desde um resfriado comum até síndromes respiratórias graves. Os casos mais novos estão sendo relacionados a uma nova variante deste vírus, denominada primeiramente como 2019-nCoV, após renomeada como Covid-19 e atualmente como SARS-CoV-2 pelo Comitê Internacional de Taxonomia de Vírus (Chaves \&Bellei, 2020).

Após declaração da OMS de que a Covid-19 tratava-se de Emergência de Saúde Pública de Importância Internacional (ESPII) e ter sido considerada como pandemia pela Organização Mundial de Saúde (OMS), o Ministério da Saúde (MS) atuou para traçar estratégias de ações em vários setores do governo e elaborar um plano de contingência (Oliveira, 2020).

Em fevereiro de 2020, este importante vírus alcançou o Brasil, tendo o primeiro caso confirmado no dia 26 de fevereiro de 2020 e em 17 de março o registro do seu primeiro óbito. O Ministério da Saúde sempre adotou a informação e a comunicação para a população, onde a imprensa também tem papel fundamental na estratégia de enfrentamento da epidemia (Oliveira, Duarte, França, \& Garcia, 2020).

Tabela 1. Distribuição dos casos de Covid-19 entre os países com maior número de casos no mês de maio de 2020.

\begin{tabular}{|c|c|c|c|c|c|c|c|c|c|}
\hline \multirow[t]{2}{*}{ Posiçäa } & \multirow{2}{*}{$\begin{array}{l}\text { PAISESE } \\
\text { TERarTORIOS }\end{array}$} & \multicolumn{2}{|c|}{ casos } & \multicolumn{2}{|c|}{ óarros } & \multirow[t]{2}{*}{ Letalidade } & \multirow{2}{*}{$\begin{array}{l}\text { Populacioio } \\
\text { (World Banls) }\end{array}$} & \multirow{2}{*}{$\begin{array}{c}\text { InCIDEENCIA } \\
\text { POA } \\
1.000 .000 \\
\text { DE HAB. }\end{array}$} & \multirow{2}{*}{$\begin{array}{c}\text { MORTALIDADE } \\
\text { POR 1.000.000 } \\
\text { HAB. }\end{array}$} \\
\hline & & $\boldsymbol{u}$ & x & $N$ & \% & & & & \\
\hline te: & $\begin{array}{l}\text { Estados } \\
\text { Unídios }\end{array}$ & 1.432 .265 & $31 \%$ & 87.180 & $28 \%$ & $6,7 \%$ & $331,915.000$ & $4.315,2$ & 262,7 \\
\hline 29 & Rissia & 290.078 & $6 \%$ & 2722 & 18 & $0,9 \%$ & 144.222 .000 & $2.015,5$ & 18,9 \\
\hline 30 & Roino Unido & 243.690 & $5 \%$ & 34.636 & $\pi \%$ & $14,7 \%$ & $67.224,000$ & $3.625,2$ & 515,2 \\
\hline $4 a$ & Brasil & 251.080 & $5 \%$ & 16.798 & $5 \%$ & $6,7 \%$ & 212.559 .000 & $1.13,2$ & 76,2 \\
\hline 50 & Espantha & 231.350 & $5 \%$ & 27.650 & $9 \%$ & $12,0 \%$ & 46.711 .000 & $4.552,8$ & 591,9 \\
\hline 69 & Italia & 225435 & $5 \%$ & 31.508 & $10 \%$ & 14,236 & 60.250 .000 & 3341,7 & 529,6 \\
\hline 70 & Ailemanhs & $174.69 ?$ & $4 \pi$ & 7.935 & $3 x$ & $4,5 \%$ & 82678.000 & $2.113,0$ & 98,0 \\
\hline 82 & Turquía & 149.435 & $3 \%$ & 4.140 & $1 \%$ & $2,6 \%$ & $84,339,000$ & $1.7 \pi, 8$ & 49,1 \\
\hline 90 & França & 140.036 & $3 \%$ & 28.059 & $9 \%$ & $20,0 \%$ & 67.443 .000 & $2.076,4$ & 46,0 \\
\hline 109 & Irà & 120.198 & $3 \%$ & 6956 & $2 \%$ & $5,8 \%$ & 83.993 .000 & $1,431,0$ & 83,2 \\
\hline & Total & 4.619 .47 & $100 \%$ & 31.847 & $100 \%$ & $6,8 \%$ & $7.775,555,471$ & 596,1 & 40,1 \\
\hline
\end{tabular}

Fonte: Ministério da Saúde (2020a).

Com a finalidade de reduzir a rápida propagação desta doença, foram implementadas medidas individuais de cuidados ao combate do coronavírus e posteriormente medidas coletivas adicionais de prevenção como: restrição a funcionamentos de escolas, universidades, locais de convívio comunitário, transporte público, locais de aglomeração de pessoas como eventos sociais e esportivos, teatro, cinema e estabelecimentos considerados como não essenciais. Todas essas medidas se tornam importantes para a manutenção da saúde das pessoas e para não colapsar o sistema de saúde brasileiro. Todas essas etapas provocaram grandes mudanças em curto prazo em uma sociedade e a saúde precisou se adaptar para o atendimento da 
população (Oliveira, Duarte, França, \& Garcia, 2020).

Dessa forma, o presente trabalho tem como justificativa, tratar de uma situação epidemiológica atípica. Sendo assim, é importante saber como os Enfermeiros Residentes vivenciaram este novo contexto em suas Unidades de Treinamento em Serviço (UTS). O estudo é relevante por abordar aspectos ligados à educação e formação do enfermeiro residente (ER), cujo assunto não se esgota uma vez que o processo educativo é contínuo e articulado ao desenvolvimento técnico-científico de uma sociedade, à exigências ao mercado de trabalho, da saúde e aos aspectos sociodemográficos e epidemiológicos de um país. Além de saberes técnicos e científicos existem outros itens a serem considerados, tais como a bagagem de experiências prévias e subjetividade presente em cada enfermeiro residente, os quais influenciarão sobre suas vivências e percepções diante de uma pandemia no cenário internacional, responsável pelo considerável número de morbimortalidade mundial. A pandemia de Covid-19 assumiu uma grande importância acadêmica e científica, com discussão e criação de protocolos organizacionais, assistências e científicos, os quais também influenciaram nos cenários de aprendizagem (escolas e campos de treinamento em serviço) e na formação de enfermeiros residentes na atuação profissional.

A contribuição da pesquisa foi relacionada ao ensino, pesquisa e assistência de Enfermagem no Curso da Residência de Enfermagem, trazendo informações e conhecimentos para uma reflexão acadêmica de docentes, tutores e preceptores, no sentido de subsidiar estratégias de ensino e aprendizagem e formulação de conteúdo programático para ER. Assim sendo, o ER ganhará oportunidades de novos saberes, para a construção de um pensamento crítico-reflexivo que o permitirá tomar decisões, atuar com segurança profissional, bem como elaborar e executar os processos de enfermagem sob supervisão nas unidades de treinamento em serviço. A universidade também poderá reformular seu planejamento estratégico com adoção de práticas pedagógicas voltadas à qualificação de ER para o mercado de trabalho. No que tange à assistência, as equipes de enfermagem nos cenários de atuação prática do ER também são favorecidas com uma atualização de conhecimentos nas relações estabelecidas com os preceptores, ER e demais membros da equipe de enfermagem na atuação na linha de frente ao cuidado de pacientes vítimas da Covid-19. No meio acadêmico, novas pesquisas poderão emergir ligadas à temática, uma vez que o conhecimento não é estático e encontra-se em constante desenvolvimento.

\section{Metodologia}

O presente trabalho está inserido no campo de pesquisa social, com abordagem qualitativa. Trata-se de uma pesquisa exploratória, que segundo Minayo (2001), é de extrema relevância, pois compreende a etapa da escolha do tópico de investigação, de delimitação do marco teórico conceitual, dos instrumentos para coleta de dados e da exploração de campo. Sua natureza qualitativa é interpretada como aquela capaz de simplificar a questão do significado e da intencionalidade como inerentes aos atos, às relações e às estruturas sociais, sendo essas últimas, tomadas tanto em sua criação quanto na sua transformação, como construções humanas significativas (Minayo, 2001).

Refere-se a uma pesquisa descritiva, que segundo Silva e Menezes (2000, p.21), visa descrever características de determinada população, assumindo assim uma forma de levantamento de dados com técnicas padronizadas.

Foi utilizada como coleta de dados a aplicação de um questionário virtual com preenchimento de formulário eletrônico individual com perguntas abertas e fechadas desenvolvidas na plataforma do Google Forms, gerando dados objetivos e subjetivos das vivências dos ER frente à pandemia. Foi enviado aos participantes por meio do correio eletrônico (email) uma carta convite com a disponibilização do link de acesso ao Termo de Consentimento e Livre Esclarecido (TCLE) e questionário. Estes endereços eletrônicos foram solicitados à coordenação da Residência de Enfermagem com concentração na área médico-cirúrgica após autorização do Comitê de Ética em Pesquisa (CEP).

Os critérios de inclusão dos participantes desta pesquisa foram os Enfermeiros Residentes matriculados regularmente no Curso de Pós-Graduação em Nível de Especialização, sob a Forma de Treinamento em Serviço para Enfermeiros, nos 
Moldes de Residência, na área de concentração Enfermagem Clínica e Cirúrgica de uma Universidade Federal do Estado do Rio de Janeiro.

Foram definidos como critérios de exclusão os Enfermeiros Residentes de outra modalidade de ensino, os que estivessem de licença maternidade e aqueles licenciados por motivos de saúde durante o período de coleta de dados.

A pesquisa foi desenvolvida de acordo com as normas da Resolução 466/2012 do Conselho Nacional de Saúde, sendo o projeto cadastrado na Plataforma Brasil e apresentado ao Comitê de Ética em Pesquisa (CEP) e direção da Universidade para sua aprovação junto com o Termo de Consentimento Livre Esclarecido (TCLE). O projeto foi aprovado no dia 15 de agosto de 2020 com o número CAAE 36621620.8.0000.5285.

Os indivíduos foram convidados, virtualmente, a participar da pesquisa e informados sobre os objetivos da pesquisa e orientados a concordar com o Termo de Consentimento Livre e Esclarecido (TCLE) apresentado na primeira etapa da pesquisa ao clicar e selecionar a seguinte opção: "Declaro ter sido informado e concordo em ser participante da pesquisa, onde automaticamente será garantido o anonimato do participante e sua concordância”. A pesquisa apresenta risco mínimo, relacionado a um desconforto do entrevistado durante sua realização, podendo desistir da pesquisa ou recusar-se a responder a qualquer questão que faça com que se sinta desconfortável a qualquer momento sem prejuízo à sua atuação como enfermeiro residente e à sua pessoa. No final do questionário é possível que o participante selecione a opção: "Send me copyofmy responses" (envie-me uma cópia das minhas respostas), antes de submetê-lo aos pesquisadores.

A coleta de dados ocorreu em novembro e dezembro de 2020. O instrumento de coleta de dados foi um questionário virtual semiestruturado e autorrespondido. O Instrumento de Coleta de Dados (ICD) é composto por perguntas abertas e fechadas, que serviram para caracterizar o perfil dos entrevistados e descrever suas vivências relacionadas à temática.

Para análise dos dados foi utilizado o método de análise de conteúdo de Bardin (2011), que por sua vez defende a ideia de que:

Um conjunto de técnicas de análise das comunicações visando a obter, por procedimentos sistemáticos e objetivos de descrição do conteúdo das mensagens, indicadores (quantitativos ou não) que permitam a inferência de conhecimentos relativos às condições de produção/recepção (variáveis inferidas) destas mensagens (Bardin, 2011, p. 47).

Desta forma, o material foi codificado, categorizado e interpretado, permitindo a formulação de categorias.

Os dados foram coletados após autorização do CEP/UNIRIO e coordenação da Residência de Enfermagem.

Os dados foram analisados e na discussão foi realizada uma comparação com a literatura da pandemia de Covid-19. Os dados qualitativos obtidos na pesquisa se tornaram importantes na construção do conhecimento, pois puderam permitir, segundo Minayo (2001), o início de uma teoria ou reformulação e classificação de abordagens concretizadas.

\section{Resultados}

Em setembro de 2020, após aprovação do Comitê de Ética e Pesquisa da UNIRIO, cujo número de aprovados é 36621620.8.0000.5285,91(noventa e um) Enfermeiros Residentes foram convidados a participar deste trabalho através de mensagem enviada pelo correio eletrônico de cada participante, na qual os ER foram orientados a acessar o link que continha o questionário on-line. Para terem acesso às perguntas, eles teriam que fazer a leitura do Termo de Consentimento Livre Esclarecido (TCLE) e, estando de acordo, marcariam a opção "concordo" para ter acesso. Mesmo com o envio de 91(noventa e um) convites, apenas 54 (cinquenta e quatro) participantes aceitaram ser entrevistados, sendo que deste total, algumas questões deixaram de ser respondidas, pois este é um direito que lhes cabia expresso no TCLE. Após este processo o questionário respondido era devolvido aos pesquisadores para realizar o tratamento, análise e discussão dos dados obtidos. 
Conhecer as vivências e saberes relatados pelo ER na atuação de pandemia de Covid-19 vem de encontro ao fato que através dos resultados obtidos nesta pesquisa, possibilitarão uma discussão e reflexão de outros profissionais acreditando que o presente tema oferece base referencial para prática assistencial.

Durante o início do desenvolvimento desta pesquisa houve a necessidade imediata de adaptação ao meio totalmente virtual, visto que o cenário de pandemia de coronavírus modificou os tradicionais métodos de entrevista pessoal, pois o isolamento social era e ainda é uma das principais formas de combate à disseminação da Covid-19. Além disso, muitos Enfermeiros Residentes (ER) se encontravam acometidos por esta doença, sendo mantidos em quarentena e afastados das Unidades de Treinamento em Serviço (UTS) para que sua saúde fosse restabelecida. Deste modo, foi necessária a realização deste trabalho por meio remoto, com o envio do Instrumento de Coleta de Dados (ICD) através do endereço eletrônico dos participantes após autorização do Comitê de Ética em Pesquisa (CEP).

Conforme descrito na metodologia, durante a realização deste estudo o entrevistado pode optar pela desistência da pesquisa ou recusar-se a responder qualquer questão que faça com que se sinta desconfortável a qualquer momento sem prejuízo à sua atuação como enfermeiro residente e à sua pessoa. Foi observado que após análise e tratamento dos dados de suas respostas, muitos participantes deixaram algumas questões em branco (tanto questões fechadas quanto questões abertas). Além disso, houve respostas duplicadas dos mesmos participantes, o que implicou em maior atenção das autoras deste trabalho no momento da análise das respostas.

Ao iniciar esta pesquisa, o objetivo era conhecer as vivências e saberes relatados pelo Enfermeiro Residente (ER) na atuação de pandemia de Covid-19, pois o cenário caótico de contaminação e morte no Brasil e mundo diante de uma nova doença, ocasionou mudanças rápidas no cotidiano da população/sociedade, inclusive na assistência de enfermagem prestada pelos ER nas instituições hospitalares.

Diante dos resultados encontrados, foram possíveis identificar várias experiências relatadas pelos ER durante sua atuação na pandemia. Estes relatos variam desde informações sobre a Covid-19, quanto a sentimentos enfrentados a sugestões de estratégias de ensino durante a pandemia.

A partir da análise das questões realizadas durante a coleta de dados foi possível compreender os impactos do cenário atual e a interferência de um cenário pandêmico no dia a dia do Enfermeiro Residente (ER) discutidas a seguir.

Após a codificação dos dados e análise dos resultados foi possível observar que quanto ao perfil dos entrevistados, 40,7\% estão inseridos no primeiro ano da residência, (R1) e 59,3\% estão inseridos no segundo ano da residência (R2).

Em relação à situação futura de pandemia de Covid-19, 51,9\% acreditavam nesta hipótese e os demais 48,1\% discordavam.

Ao serem questionados quanto à disponibilidade de Equipamentos de Proteção Individual em suas unidades de Treinamento em Serviço, 96,3\% dos entrevistados afirmaram ter recebido estes equipamentos e apenas 3,7\% negaram o acesso a este material.

Quanto ao manejo dos pacientes positivos para coronavírus a preceptoria do curso de enfermagem se fez presente dando suporte às demandas acadêmicas em $61,1 \%$ dos casos e em 38,9\% os participantes relataram como ausente.

Ainda com relação à preceptoria e da Educação Permanente da UTS, 57,3\% dos ER concordaram que participaram do treinamento com a preceptoria para prestar atendimento aos pacientes infectados pela doença e $46,3 \%$ destes enfermeiros não foram contemplados.

No que se refere à doença propriamente dita, 64,3\% disseram ter sido infectados pela Covid-19 e foram afastados de suas atividades laborais após realização de exame confirmatório e 37,5\% também estiveram afastados de suas atividades, porém sem a realização do teste confirmatório. Os dois grupos mantiveram cuidados domiciliares. 
Os testes realizados pelos ER correspondem a 70,4\% teste convencional (RT-PCR) e 29,6\% teste rápido. Já o retorno após o período de afastamento aconteceu sem a necessidade de realização de exames em $75 \%$ dos casos e apenas $25 \%$ referiram ter realizado exame para retornar às atividades.

Ao relacionar o afastamento do enfermeiro residente com o acometimento de seus familiares, foi evidenciado pela maioria de $75 \%$ a não contaminação de Covid-19 e 25\% dos com acometimento concomitante de algum familiar.

Grande parte dos entrevistados relatou que seus familiares não realizaram exames quando estavam adoecidos, representando $65,5 \%$ da pesquisa e 34,5\% sim. Nesta questão houve abstenção de 25 participantes.

Para a confirmação da Covid-19 nos familiares dos entrevistados, 54,5\% responderam ter realizado o teste convencional, enquanto 45,5\% afirmaram terem realizado o teste rápido. Houve abstenção de 43 entrevistados.

Aos entrevistados que testaram positivo para Covid-19, o tempo de recuperação foi entre sete e quatorze dias em 52\%, mais de quatorze dias em $24 \%$ e menos de sete dias em outros $24 \%$. Neste caso, houve abstenção de 29 participantes.

\section{Discussão}

No contexto de uma pandemia como a da Covid-19, as abordagens tradicionais precisam evoluir junto às vivências dos profissionais de saúde, assim como todas as práticas sustentadas, nos pressupostos do campo de assistência aos quais atuam o ER, que precisam ser compartilhadas, para que as melhorias, através do saber adquirido dentro do cenário pandêmico fossem relatadas e interpretadas, contribuindo com a comunidade acadêmica, e assim oferecerem subsídios, para uma melhor assistência de enfermagem prestada pelo ER.

Conhecer as vivências e saberes relatados pelo ER na atuação de pandemia de Covid-19 veio de encontro ao fato de que através dos resultados obtidos nesta pesquisa, se possibilitou uma discussão e reflexão de outros profissionais, permitindo oferecer base referencial para prática assistencial.

Esta pesquisa exigiu imediata adaptação ao meio virtual, visto que o cenário da pandemia de coronavírus modificou os tradicionais métodos de entrevista, pois o isolamento social era e ainda é uma das principais formas de combate à disseminação da Covid-19. Deste modo, foi necessária a realização deste trabalho por meio remoto, com o envio do Instrumento de Coleta de Dados (ICD) através do endereço eletrônico dos participantes após autorização do Comitê de Ética em Pesquisa (CEP).

Conforme descrito na metodologia, durante a realização deste estudo o entrevistado pode optar pela desistência da pesquisa ou recusar-se a responder a qualquer questão que faça com que se sinta desconfortável a qualquer momento sem prejuízo à sua atuação como enfermeiro residente e à sua pessoa. Durante a análise e tratamento dos dados, observou-se que, muitos participantes deixaram algumas questões em branco (tanto questões fechadas quanto abertas), o que não interferiu na análise e se respeitou a Resolução CNS 466/2012 (Brasil, 2012). Além disso, houve respostas duplicadas dos mesmos participantes, o que implicou em maior atenção das autoras deste trabalho no momento da análise das respostas.

Diante dos resultados encontrados, foi possível identificar várias experiências relatadas pelos ER durante sua atuação na pandemia e compreender os impactos do cenário atual e a interferência de um cenário pandêmico no dia a dia do Enfermeiro Residente (ER).

Identificou-se que o total de entrevistados 40,7\% encontravam-se no primeiro ano (R1) e 59,3\% no segundo ano (R2). Totalizando 54 respondentes.

A maioria concordou que a Covid-19 se tornaria pandemia 51,9\%. Este fato fica evidenciado pela Fundação Oswaldo Cruz (FIOCRUZ), pois se trata de situação emergente de saúde pública. 
Neste cenário de pandemia, 95,2\% dos ER tiveram acesso à capacitação/treinamento sobre como realizar, de forma segura, a paramentação e a desparamentação dos Equipamentos de Proteção Individual (EPI) e higienização das mãos durante sua atuação com os pacientes e, principalmente, com os infectados pela doença.

Além disso, durante o manejo dos pacientes positivos para coronavírus a preceptoria de enfermagem do curso de residência esteve presente proporcionando suporte às demandas acadêmicas em $61,1 \%$ dos casos, mas em quase $40 \%$ os ER relataram não ter recebido este apoio profissional de qualquer enfermeiro, o que gera preocupação, pois o preceptor é o profissional de referência no cenário de Treinamento em Serviço.

No entanto, quando questionados sobre a participação do ER junto da preceptoria e educação permanente em suas UTS para o manejo dos pacientes diagnosticados com a doença, 53,7\% afirmaram ter sido contemplados neste aspecto.

Este resultado reforça o que é difundido pela FIOCRUZ (Dominguez, 2020) na situação de pandemia, onde é esperada a criação de novos protocolos que exigem a capacitação dos profissionais da área de saúde, visto que estão regularmente expostos ao risco de contaminação pelo novo coronavírus.

Diante de uma circunstância tão inesperada como foi a pandemia de Covid-19, além de trabalhar em situações de superlotação nas unidades de saúde e com sobrecarga de trabalho, muitos integrantes da equipe acabaram se contaminado pela doença e passaram de profissional de saúde a paciente.Constatando-se dentre os ER que 47,4\% contraíram a doença e ficaram afastados em cuidados domiciliares de forma assintomática e outros 52,6\% disseram ter apresentado sintomas tais como: tosse, febre, diarreia, anosmia, ageusia, coriza, dispneia, precordialgia,

No que diz respeito ao afastamento dos profissionais de saúde que estão em contato direto com a doença, Ribeiro, Oliveira, Silva e Souza (2020) acreditam que por estes serem um grupo diretamente ligado aos pacientes infectados pela Covid-19, acabam sendo um grupo mais específico para a infecção. Tal situação acaba apresentando-se como um risco biológico, onde se percebe o aumento do risco de contaminação, principalmente ao realizar procedimentos em vias aéreas ou próximas a elas.

A Organização Pan-Americana de Saúde (OPAS) juntamente com a Organização Mundial de Saúde (OMS)(2020) acredita que os sintomas costumam ocorrer de forma leve e evolução gradual.

Desses profissionais infectados, os que correspondem a 64,3\% fizeram o teste confirmatório de Covid-19 antes de serem afastados de fato de suas atividades laborais e assim permanecendo em cuidados domiciliares. Dos que realizaram os testes, 70,4\% corresponderam ao teste convencional (RT-PCR) e 29,6\% ao teste rápido. O retorno, após o período de afastamento, aconteceu sem a necessidade de realização de exames em 75\% dos casos. Este procedimento está de acordo com as recomendações do Ministério da Saúde (2020b), advertindo que o profissional de saúde que foi afastado sintomaticamente, poderá retornar às suas atividades após 14 dias do primeiro resultado positivo do teste, com pelo menos 3 dias (72 horas) de recuperação sem presença de sintomas febris e com melhora observável do quadro respiratório.

Ao relacionar o afastamento com o acometimento de familiares, algo que parecia improvável foi evidenciado pela maioria de $75 \%$ que não houve familiares contaminados pela Covid-19, apenas $25 \%$ dos sujeitos referiram o acometimento concomitante de algum familiar, fato este, pode ser explicado pela boa conduta em relação às boas práticas na execução dos cuidados de enfermagem, que foram alcançados através de treinamento e capacitação. A portaria conjunta $n^{\circ}$ 20/2020 do Ministério da Economia em conjunto com a Secretaria Especial de Previdência e Trabalho (2020) também recomenda que os contactantes de casos confirmados devem ficar afastados por 14 dias de suas atividades laborais.

Onde se discute sobre o familiar ter realizado exames para constatação da doença, ficou esclarecido que uma pequena parcela de $34,5 \%$ realizou os exames e destes $54,5 \%$ afirmam ter realizado o teste convencional e 45,5\% afirmam ter realizado o teste rápido. 
Exames estes que são compreendidos pelo Ministério da Saúde (2020b) como teste molecular/convencional, conhecido como RT-PCR, que se mantém como teste laboratorial de melhor escolha para o diagnóstico de pessoas infectadas sintomáticas na fase aguda da doença, que ocorre entre o $3^{\circ}$ e $7^{\circ}$ dia. Sua realização é feita através da utilização de dois swabs, sendo um para a orofaringe e outro para a nasofaringe. Já o outro método se dá através do teste imunológico/sorológico, podendo ser realizado por duas técnicas diferentes: ELISA (enzyme-linkedimmunosorbentassay) e ensaios imunocromatográficos, mais conhecido como "teste rápido", ambas as técnicas realizadas através de uma amostra de sangue, visando a detecção de anticorpos (IgG e IgM) produzidos pelo sistema imunológico dos pacientes em resposta a uma infecção pelo SARS-CoV-2. Estes devem ser realizados pelo menos após 7 dias do início dos sintomas e podem possuir variação de sensibilidade e especificidade dos testes de acordo com o fabricante, podendo acarretar em resultados falso-positivos.

Articulando sobre o tempo de recuperação, $52 \%$ dos entrevistados relataram ter demorado entre sete e quatorze dias para observar melhora em seu estado clínico e alívio de sintomas, $24 \%$ com o relato de mais de quatorze dias e $24 \%$ obtiveram melhora em menos de sete dias. Vale ressaltar que este período é fundamental para que a recuperação ocorra como esperado e que depende da quantidade de dias, do nível da infecção, devendo em qualquer um dos casos serem seguidos os mesmos protocolos para realização do tratamento em domicílio.

Nesta etapa da discussão, são abordados os resultados das questões abertas, desta forma será iniciada a análise temática de conteúdo de Bardin (2011) que permite a inferência de conhecimentos relativos às condições de produção/recepção destas mensagens.

As respostas das questões foram denominadas com Unidades de Respostas UR, estas geraram as Unidades de Significação US, sendo discutidas as mais citadas pelos entrevistados. A partir disto, foi considerada a análise de quatro categorias temáticas importantes, que serão discutidas a seguir:

\section{Categoria 1: Percepção do Enfermeiro Residente quanto ao impacto da pandemia de Covid-19 em seu cotidiano.}

Dentre a leitura das respostas dos entrevistados em relação a esta categoria, foram abordados sentimentos que emergiram durante sua atuação no cenário de pandemia. Essa categoria possui 42UR. Diante disso percebe-se a relevância desta temática. Assim as US discutidas nesta categoria são: psicológico (17UR), medo (11UR), estresse (08UR), instabilidade emocional (07 UR), saúde mental (06 UR), ansiedade (4 UR),

O impacto foi uma profunda tristeza pela forma que as pessoas estavam morrendo, sozinhas, sem seus familiares, com dor e sem o direito a uma despedida humana. O medo de estar nesse lugar eventualmente seja como paciente ou familiar me apavora (ER2).

No início fiquei isolada da família, me senti claustrofóbica dentro de casa e muito instável emocionalmente (ER4).

Medo de adquirir a doença, medo de transmitir a doença para minha família, estresse em sobrecarga de trabalho (ER24).

Maior pressão psicológica na rotina da unidade, maior despreparo e medo dos profissionais diante da nova doença (ER34).

Mudou minha vida. Eu não tive a doença, mas meus pais tiveram. Meu pai quase morreu, ficou internado 23 dias. Eu tive que continuar firme na residência mesmo sem saber o desfecho. Vi profissionais entrarem em pânico. Equipes inteiras sem saber o que fazer com tantos pacientes internados em estado gravíssimo. Vi pessoas entrarem em 
depressão. Vi 3 vizinhos meus morrerem. Vi pacientes queridos morrerem...E eu que ajudo financeiramente em casa, tive medo de ter a doença e acabar morrendo também...e acabar deixando minha família passar necessidade... enfim... ainda há esse risco, neh? (ER46).

Estas falas deixam claro o sentimento de impotência dentro de um cenário hospitalar pandêmico, pois os pacientes acometidos pela doença estavam sofrendo num ambiente hostil e isoladas de outras pessoas, porque infelizmente no caso do novo coronavírus o paciente contaminado não tem direito a visitas nem a acompanhante devido ao risco de contaminação, como relatado na fala do entrevistado ER2.

Os Enfermeiros Residentes que estavam atuando na linha de frente exaustivamente apresentaram desequilíbrio emocional relacionado à sobrecarga de trabalho evidenciada pelo aumento abrupto no número de internações, situação que gerou colapso da rede de saúde. O manejo desses pacientes durante a realização dos cuidados de enfermagem também ocasionaram insegurança, pois os profissionais de saúde temiam a contaminação de si e posteriormente seus familiares e amigos. Dalri, Silva, Mendes e Robazzi (2014) reforçam que um estresse é gerado acerca das condições de prestação e produção de serviços, com a intensificação do trabalho, aumento na carga horária no fluxo de internações e aumento das responsabilidades.

Todos estes sentimentos vão de encontro com estudo recente de Teixeira, Soares, Souza, Lisboa, Pinto, Andrade, et al.(2020)que relata que as circunstâncias geradas pela pandemia requerem maior atenção aos profissionais de saúde, principalmente no que diz respeito aos aspectos que afetam à sua saúde mental. O que de fato gerou aumento de sintomas depressivos, de ansiedade, entre outros sintomas psicossomáticos.

\section{Categoria 2: Obstáculos percebidos pelo Enfermeiro Residente na prática assistencial e no ensino teórico durante pandemia de Covid-19}

Nesta categoria são descritas as dificuldades evidenciadas pelos ER no campo prático-assistencial e na continuidade das aulas teóricas, a qual possui 38 UR e 49 US são elas: modificação no perfil dos pacientes internados (09 UR), descaracterização dos setores de internação(07 UR), alteração de carga horária prática (07 UR), interrupção das aulas (05 UR).

[...] Muitos setores deixaram de funcionar ou tiveram suas atividades reduzidas, com isso houve menos oportunidade de aprender e vivenciar algumas situações (ER14).

[...] A mudança na escala que foi reduzida, e a rotina do hospital também, com muitos setores fechados, o ensino ficou prejudicado (ER20).

As aulas foram suspensas durante um longo período, e não tivemos nenhum treinamento ou orientação da mesma (ER 01).

[...] As aulas não são mais presenciais. Muitos congressos deixaram de ser realizados. Além de, muitas vezes, internarmos os pacientes "fora de clínica". Como sou residente de cardiologia, admiti muitos pacientes com COVID que não tinham repercussões cardiovasculares (ER30).

[...] O fluxo do hospital onde trabalho modificaram e setores que deveria passar, mas não pude passar e outros eu estava somente como um aporte de trabalho e não como residente, fora que os profissionais não estavam com paciência e nem vontade de ensinar (ER38). 
Segundo os entrevistados, no que se refere à aprendizagem teórica e a prática assistencial, alguns relatos expressaram a transformação tanto do perfil dos pacientes quanto a estrutura física que atendeu o público que necessitava de atendimento médico, neste caso, predominantemente com Covid-19.

Logo no início devido à alta demanda de pacientes contaminados pela doença, houve a necessidade de alteração do número de vagas disponíveis em enfermarias diversas, como a unidade coronariana que teve seus leitos reduzidos para que mais pacientes de Covid-19 fossem internados já que a demanda era maior. Muitos setores tiveram que ser fechados, outras unidades de terapia intensiva foram reconfiguradas especificamente como unidades de terapia intensiva de Covid-19, levandose em consideração a gravidade dos pacientes e assim proporcionando a descaracterização setorial. Assim como Daumaset al. (2020) explica ao trazer a ideia de que para melhor embate à pandemia os serviços de saúde devem otimizar os cuidados prestados e reestruturar a rede de assistência, afirmando que além de ser importante o número do aumento de leitos em UTI e de respiradores, também é relevante manter a organização institucional para ofertar acesso apropriado a esses leitos.

Para Barbosa, Gomes, Souza e Gomes (2020), uma das formas de diminuir a vulnerabilidade em que se encontram os profissionais de saúde neste momento de pandemia seria a redução da carga horária destes trabalhadores. A fim de evitar um excesso de exposição dos ER ao Covid-19 e possível adoecimento em massa dos ER, muitos preceptores das UTS optaram por redução da carga horária prática destes profissionais. Embora este ato fosse necessário, o aprendizado de outras patologias foi prejudicado segundo relato dos entrevistados ER 14 e ER 20.

Com relação às aulas teóricas, muitos pontuaram a suspensão das aulas, que depois foram retomadas através de plataformas digitais. De acordo com Prata, Mello, Costa e Silva e Faria (2020), o ensino remoto está sendo inovador no curso de residência, visto que o distanciamento social é uma das principais formas de evitar o contágio da doença. Nesta modalidade de ensino é importante que tanto os discentes quanto os docentes dominem as ferramentas digitais, tenham acesso à internet $\mathrm{e}$ disponham de disciplina para ficarem focados nos assuntos abordados e o aprendizado seja alcançado.

\section{Categoria 3: Aprendizagem do ER a partir da experiência proporcionada pela pandemia}

Este momento trata sobre o aprendizado dos ER em que foram encontradas 39 UR e 13 US distribuídos da seguinte forma:trabalhar mediante situação crítica (09 UR), uso do EPI com responsabilidade, (07 UR), cuidados com a saúde mental (07 UR), promover ao cuidado a paciente grave (06 UR).

Maior conhecimento sobre o paciente crítico (ER1).

Aprender a lidar com situações adversas e inesperadas e nunca perder a esperança de dias melhores (ER5).

Que devemos sempre nos proteger utilizando os EPI's. E que doenças novas sempre vão existir, devemos nos adaptar (ER21).

Como atuar frente a uma pandemia, como utilizar os EPI's no isolamento respiratório com mais responsabilidade (ER37).

Cuidados com o paciente grave, avaliação de parâmetros respiratórios/ventilatórios (ER44).

Diante da situação de emergência de saúde pública, aprendizados importantes dos ER tornaram-se protagonistas do cuidado, como atuar em situação crítica. Durante a pandemia a tomada de decisões imediatas foi fundamental para salvar vidas. 
Ainda assim os ER destacaram o uso responsável e racional do Equipamento de Proteção Individual (EPI), pois é essencial na proteção do profissional de saúde principalmente no caso de doenças infectocontagiosas. Sendo assim Soares, Penna, Pinno, Durgante, Saul, Farão e Lima (2020) destacam que os trabalhadores necessitam se conscientizar sobre a importância de utilizar os EPI's de forma coerente e segura, estando cientes também de seus direitos de obtenção em quantidades e qualidades necessárias de forma que possam auxiliar as necessidades assistenciais, levando em consideração grau de cuidado e tipo de atividade a ser executada, preservando a segurança dos pacientes e sua própria saúde.

Muitos entrevistados reconheceram o aprendizado da assistência de enfermagem ao doente em situação crítica. Este perfil de pacientes de acordo com Soares, Souza, Silva, César, Souto e Leite (2020) requer da equipe da Unidade de Terapia Intensiva conhecimento e cuidados específicos de acordo com a necessidade e especificidade de cada indivíduo, visando à estabilidade hemodinâmica e assistência competente a beira leito.

Todos esses elementos contribuíram para refletir sobre a importância do cuidado da saúde mental do ER em seu cotidiano.A Organização Mundial de Saúde OMS (2020) também defende este fator de bem estar psicossocial, pois este equilíbrio é necessário para os profissionais de saúde desenvolverem suas atividades de modo mais adequado.

\section{Categoria 4: Sugestões de aperfeiçoamento para o curso de Pós-Graduação nos moldes de Residência de Enfermagem}

A presente categoria aborda as sugestões de estratégias para o aperfeiçoamento do curso de residência após vivência de pandemia. Através de 26 UR e 17 US, treinamentos sobre Covid-19 (06 UR), intensificação das aulas teórico-práticas (06 UR) e apoio psicológico (UR 05) foram discutidas.

Para aprimorar as estratégias de ensino aprendizagem do curso de pós-graduação nos moldes de residência de enfermagem durante a pandemia foram elencadas algumas sugestões por parte dos entrevistados revelados nas falas a seguir:

Treinamento/aulas sobre a doença antes de ir para setores com paciente Covid (ER15).

Acho que uma aula com algum psicólogo de como lidar com situações assim seria interessante, pois como residente, muitas vezes não sabia como processar tudo que acontecia ao meu redor no hospital (ER28).

Treinamentos para situações de crise como a pandemia (ER30).

O que deveria melhorar é oferecimento de apoio psicológico e mostrar que a unidade e a Universidade se importam com o residente (ER 34$)$.

A grade curricular deveria dispor de conteúdos mais voltados para a prática e avaliação clínico-assistencial do residente desde seu primeiro ano (ER42).

Os treinamentos específicos para o manejo de pacientes portadores de Covid-19 em conjunto com a educação permanente devem estar sempre disponíveis dentro das instituições de saúde, pois é através da atuação deste grupo, que os profissionais de saúde são contemplados com orientações seguras e atualizadas sobre a doença. Além disso, a educação permanente elabora protocolos, normas e atualiza fluxos conforme a necessidade institucional. Isto é reforçado em uma pesquisa recente de Zingra, Silva, Fernandes, Junior e Batista (2020), em que o processo de educação permanente pode ser um facilitador para melhorar a estratégia de cuidado e integrar harmonicamente as equipes que atuam na linha de frente do Covid19.

Em contrapartida as Universidades poderiam rever as temáticas das aulas teóricas e práticas a serem abordadas de modo que atendam as expectativas dos alunos nos cenários de prática hospitalar, pois muitos entrevistados relataram 
insatisfação como na fala de ER 42. De acordo com o Regulamento da Universidade Federal do Estado do Rio de Janeiro o curso de especialização nos moldes de residência (2018), os alunos contam com o direito de oferta de disciplinas e atividades em número e qualidade que viabilizem as diversas etapas do Programa incluindo receber a orientação condizente com a direção de seus estudos e com a natureza de suas atividades.

Realizar alguma atividade que proporcione apoio psicológico é fundamental, já que a pandemia causou estresse adicional aos residentes. Diferente de outros momentos, os profissionais tiveram a experiência de ver inúmeros pacientes em luta pela vida em condições precárias, trabalhadores exaustos, com medo de serem acometidos pela doença durante o desenvolvimento de suas atividades, pacientes morrendo em meio à solidão. Estes fatores contribuem para o surgimento do sentimento de frustração, e precisam de alguma forma ser trabalhados para restabelecer o equilíbrio neste aos ER. Contudo, Schmidt, Crepaldi, Bolze, Neiva-Silva e Demenech (2020) afirmam que devem ser levadas em consideração medidas que busquem a redução dos impactos psicológicos provocados durante a pandemia, contando com a ajuda de psicólogos para promoção da saúde mental e diminuição dos efeitos negativos ocasionados pela situação atual.

\section{Conclusão}

De acordo com o objetivo inicial, ao desenvolver esta pesquisa, foi possível identificar quais foram as vivências e saberes relatados pelos enfermeiros residentes de uma universidade do estado do Rio de Janeiro. Após análise dos resultados, ficou evidente que o cenário de pandemia causou muitas mudanças no cotidiano da sociedade, das instituições de saúde e dos profissionais de saúde, em especial na atuação do Enfermeiro Residente (ER).

O contexto de pandemia de coronavírus evidenciou neste estudo o desgaste psicológico durante o curso de PósGraduação na modalidade de Residência em enfermagem, mas também fez com que os avanços tecnológicos pudessem ser inseridos de maneira a garantir a carga horária teórica de $20 \%$ preconizada pelo curso. Apesar das aulas teóricas terem sido suspensas por um período, elas foram retomadas através de plataformas digitais.Muitos entrevistados relataram que há necessidade de readequação dos temas abordados pela instituição de ensino, pois foi evidenciada uma lacuna entre as aulas oferecidas e a prática hospitalar que o ER encontra em sua Unidade de Treinamento em Serviço (UTS), o que causa insegurança na prestação de assistência de enfermagem.

Outro ponto relevante deste estudo foi o impacto na assistência aos pacientes infectados pelo novo coronavírus, pois vivenciar as lotações das unidades com este perfil de paciente causou instabilidade emocional do ER que acarretou em prejuízo no desempenho de suas atividades assistenciais. Todos esses fatores culminaram em desgaste relacionado à saúde mental dos entrevistados.

Quando observados os altos índices de internações de doentes infectados pela Covid-19 nas instituições de saúde, deve-se lembrar que a disponibilização do Equipamento de Proteção Individual (EPI) é imprescindível durante a assistência de enfermagem e que utilizá-los de maneira racional e responsável proporciona segurança à saúde do ER, assim como reduz a disseminação entre os pacientes que ficam sujeitos a esses cuidados.

Ainda neste contexto dos EPI's cabe salientar que a presença da Educação Permanente das UTS em conjunto com os preceptores foram fundamentais na realização de capacitação/treinamento neste processo de paramentação e desparamentação, higienização das mãos para que houvesse sucesso na assistência prestada.A conscientização dos profissionais de saúde e a modificação dos hábitos da equipe multidisciplinar também refletem de forma positiva na recuperação dos doentes e prevenção de novos casos. Prova disso são os dados obtidos na pesquisa quanto à infecção dos ER e de seus familiares, onde ficou constatada a baixa contaminação por coronavírus, destacando a relevância de boas práticas de biossegurança.

No início da pandemia, muitas dúvidas foram lançadas em relação ao manejo dos pacientes e isto fez com que os profissionais de saúde que atuam na linha de frente, apesar de sua árdua rotina, desenvolvessem diante do caos medidas de 
biossegurança a novos protocolos institucionais que abrangessem todos os cuidados a serem ofertados aos pacientes, desde a admissão na emergência até mesmo nos CTI's de Covid-19. Desse modo, esses profissionais podem lidar com a doença de forma segura, já que desempenham cuidados diários a pacientes suspeitos ou infectados e assim elevar a qualidade da assistência prestada.

Como sugestão, as autoras defendem a ideia da oferta de apoio psicológico durante o período de desenvolvimento da Residência, pois a carga horária prática extensa acompanhadas das atividades teóricas se tornam desgastantes e no caso da pandemia em que se somou as questões de aumento de número de internações de pacientes, com rápido agravamento do quadro clínico, altos índices de óbitos, isolamento social, tiveram um impacto elevado a saúde mental dos enfermeiros, causando esgotamento emocional.

É preciso que o curso faça uma reavaliação dos temas das aulas propostos aos alunos, de modo que as expectativas sejam contempladas de acordo com a assistência que precisa ser realizada nas instituições de saúde, principalmente assuntos relacionados à assistência de paciente crítico. Também é necessário melhorar a interação do corpo docente e discente no manuseio das ferramentas tecnológicas, para que ao longo do curso esse processo se desenvolva de forma positiva e que isto não seja empecilho no aprendizado.

Todos esses aspectos certamente irão contribuir para que os cursos de molde residências se tornem cada vez melhores, e possibilitem aos egressos sucesso em sua carreira profissional.

Espera-se que este artigo possa fomentar novos estudos e que os impactos evidenciados nesta pesquisa contribuam para ampla reflexão e discussão do quanto o cenário pandêmico pode influenciar nas atividades desenvolvidas não somente pelos enfermeiros residentes, mas também a todos os profissionais de saúde que atuam diariamente dentro das instituições hospitalares.

\section{Referências}

Barbosa, D. J., Gomes, M. P., Souza, F. B. A., \& Gomes, A. M. T. (2020). Fatores de estresse nos profissionais de enfermagem no combate à pandemia da COVID-19: síntese de evidências. Comunicação em Ciências Saúde, 31, 32-47. 10.51723/ccs.v31iSuppl\%201.651.

Bardin, L. (2011). Análise de conteúdo. Edições 70.

Brasil. (2005a). Decreto n ${ }^{\circ} 11.129$, de 30 de junho de 2005. Institui a Residência em Área Profissional de Saúde e cria a Comissão Nacional de Residência Multiprofissional em Saúde. Diário Oficial da União. Brasília: Poder Executivo, 30 jun. 2005. http://www.residenciamultiprofissional.ufes. br/legisla\%C3\% A7\% $3 \%$ A3o.

Brasil. (2005b). Resolução no 05, de 07 de novembro de 2005. Dispõe sobre a carga horária dos programas de Residência em Área Profissional de Saúde nas modalidades multiprofissional e uniprofissional e sobre a avaliação e a frequência dos profissionais da saúde residentes. Brasília: Comissão Nacional de Residência Multiprofissional em Saúde, DOU nº 127, seção 1, p. 34, nov. 2014. http://www.legisweb.com.br/legislacao/?id=276672.

Brasil. (2019). Resolução no 5244, de 26 de novembro de 2019. Dispõe sobre o Regimento Geral dos cursos de Pós-Graduação Latu Sensu da Universidade Federal do Estado do Rio de Janeiro. Rio de Janeiro: Universidade Federal do Estado do Rio de Janeiro, nov. 2019. http://www.unirio.br/fale-conosco1/propg/diretoria-de-pos-graduacao/legislacao-1/regimentos/regimento-geral-da-pos-graduacao-lato-sensu/view.

Brasil. (2010). Resolução nº 3, de 04 de maio de 2010. Dispõe sobre a duração e a carga horária dos programas de Residência Multiprofissional em Saúde e de Residência em Área Profissional de Saúde e sobre a avaliação e a frequência dos profissionais da saúde residentes. Brasília: Comissão Nacional de Residência Multiprofissional em Saúde, seção 1, p. 14-15, mai. 2010. http://portal.mec.gov.br/index.php?option=com_docman\&view=download\&alias=15449-resolcnrms-n3-04maio-2010\&Itemid=30192.

Brasil. (2012). Resolução $\mathrm{n}^{\circ}$ 466, de 12 de dezembro de 2012. Conselho Nacional de Saúde. Brasília: Ministério da Saúde. http://bvsms.saude.gov.br/bvs/saudelegis/cns/2013/res0466_12_12_2012.html.

Brasil. (2014). Resolução n ${ }^{\circ}$ 5, de 07 de novembro de 2014.Dispõe sobre a duração e a carga horária dos programas de Residência em Área Profissional da Saúde nas modalidades multiprofissional e uniprofissional e sobre a avaliação e a frequência dos profissionais da saúde residentes.Brasília: Comissão Nacional de Residência Multiprofissional em Saúde, DOU: 07.11.2014. http://www.normaslegais.com.br/legislacao/Resolucao-cnrms-5-2014.htm.

Brasil. (2020). Definições de afastamento laboral para profissionais de serviços essenciais. Secretaria de Saúde do Governo do Estado do Espírito Santo: Nota técnica Covid-19 $\mathrm{n}^{\circ}$ 03/2020. https://saude.es.gov.br/Media/sesa/coronavirus/No tas\%20T\%C3\%A9cnicas/NOTA\%20T\%C3\% 89CNICA\%20COVID.19\%20N.\%2003.20.\%20Defini\%C3\%A7\%C3\%B5es\%20de\%20Afastamento\%20Laboral.pdf 
Carvalho, D. J. M. D., Silva, R. M. O., Fernandes, J. D., Cordeiro, A. L. A. O., Santos, O. M. B., Silva, L. S., \& Silva, E. A. L. (2019). Egressos de Residência em Enfermagem e o mercado de trabalho. Revista Enfermagem UFPE OnLine, Recife, 13(e234616), 1-8. 10.5205/1981-8963.2019.238381.

Chaves, T. S. S., \& Bellei, N. (2020). SARS-COV-2, o novo Coronavírus: uma reflexão sobre a Saúde Única (One Health) e a importância da medicina de viagem na emergência de novos patógenos. Revista de Medicina (São Paulo), 99(1). http://www.revistas.usp.br/revistadc/article/view/167173.

Dalri, R. C. M. B., Silva, L. A., Mendes, A. M. O. C., \& Robazzi, M. L. C. C. (2014). Carga horária de trabalho dos enfermeiros e sua relação com as reações fisiológicas do estresse. Revista Latino-Americana de Enfermagem, 22(6), 959-965. 10.1590/0104-1169.3292.2503.

Daumas, R. P., Silva, G. A., Tasca, R., Leite, I. C., Brasil, P., Greco, D. B., \& Campos, G. W. S. (2020). O papel da atenção primária na rede de atenção à saúde no Brasil: limites e possibilidades no enfrentamento da COVID-19. Cadernos de Saúde Pública, 36(6), p. 1-7. 10.1590/0102-311x00104120.

Dominguez, B. (2020). Covid-19: que vírus é esse?. Matéria publicada no site da Fundação Oswaldo Cruz, no dia 30 de março de 2020. http://portal.fiocruz.br/noticia/covid-19-que-virus-e-esse.

Minayo, M. C. de S. (Org.). (2001). Pesquisa social. Teoria, método e criatividade. (18a ed.), Vozes.

Silva, E. L., \& Menezes, E. M. (2000). Metodologia da pesquisa e elaboração da dissertação. UFSC/PPGEP/LED.

Ministério da Economia. (2020). Portaria conjunta no 20/2020. Ministério da Economia em conjunto com a Secretaria Especial de Previdência e Trabalho. https://www.in.gov.br/en/web/dou/-/portaria-conjunta-n-20-de-18-de-junho-de-2020-262408085.

Ministério da Saúde. (2020a). Boletim Epidemiológico Especial - COE-Covid19.nº16. Publicado em 18 de maio de 2020 pela Secretaria de Vigilância em Saúde. http://portalarquivos.saude.gov.br/images/pdf/2020/May/21/2020-05-19---BEE16---Boletim-do-COE-13h.pdf.

Ministério da Saúde. (2020b). O que é Covid-19. http://coronavirus.saude.gov.br.

Organização Pan-Americana de Saúde [OPAS]/Organização Mundial de Saúde [OMS]. (2020). Folha informativa - COVID-19 (doença causada pelo novo coronavírus). https://www.paho.org/pt/covid19.

Oliveira, W. K., Duarte, E., França, G. V. A., \& Garcia, L. P. (2020). Como o Brasil pode deter a COVID-19. Epidemiologia e Serviços de Saúde, Brasília, 29(2). 10.5123/s1679-49742020000200023.

Prata, J. A., Mello, A. S., Costa e Silva, F. V., \& Faria, M. G. A. (2020). Mediações pedagógicas de ensino não formal da enfermagem durante a pandemia de COVID-19. Revista Brasileira de Enfermagem, 73(2), 1-5. 10.1590/0034-7167-2020-0499.

Ribeiro, A. P., Oliveira, G. L., Silva, L. S., \& Souza, E. R. (2020). Saúde e segurança de profissionais de saúde no atendimento a pacientes no contexto da pandemia de Covid-19: revisão de literatura. Revista Brasileira de Saúde Ocupacional, 45, e25. 10.1590/2317-6369000013920.

Schmidt, B., Crepaldi, M. A., Bolze, S. D. A., Neiva-Silva, L., \& Demenech, L. M. (2020). Saúde mental e intervenções psicológicas diante da pandemia do novo coronavírus (COVID-19). Estudos de Psicologia. 37(e200063), 1-13. 10.1590/1982-0275202037e200063.

Silva, E. L., \& Menezes, E. M. (2000). Metodologia da pesquisa e elaboração de dissertação.Programa de Pós-graduação em Engenharia de Produção: Universidade Federal de SantaCatarina, Florianópolis, 118p.

Soares, R. S. A., Penna, M. A., Pinno, C., Durgante, V. L., Saul, A. M. R., Farão, E. M. D., \& Lima, S. B. S. (2016). Vivências de residentes enfermeiros no programa de residência multiprofissional em saúde. Revista Saúde, Santa Maria, 43(1), 13-21. 10.5902/2236583414826.

Soares, S. S. S., Souza, N. V. D. O., Silva, K. G., César, M. P., Souto, J. S. S., \& Leite, J. C. R. A. P. (2020). Pandemia de Covid-19 e o uso racional de equipamentos de proteção individual. Revista Enfermagem UERJ, 28, 1-6. 10.12957/reuerj.2020.50360.

Teixeira, C. F. S., Soares C. M., Souza, E. A., Lisboa, E. S., Pinto, I. C. M., Andrade, L. R., et al. (2020). A saúde dos profissionais de saúde no enfrentamento da pandemia de Covid-19. Ciência \& Saúde Coletiva, 25(9), 3465-3474. 10.1590/1413-81232020259.19562020.

Universidade Federal do Estado do Rio de Janeiro. (2018). Boletim n. 06, de 29 de março de 2018. Regulamento do curso de pós-graduação em nível de especialização, sob a forma de treinamento em serviço para enfermeiros, nos moldes de residência. Rio de Janeiro. http://www.unirio.br/cpgemr/arquivos/REGULAMENTO\%20DO\%20CURSO.06.04.18.pdf.

Zingra, K. N., Silva, A. de C. R., Fernandes, A. J. de M., Junior, A. G. B., \& Batista, M. G. (2020). Educação permanente para profissionais da área da saúde como estratégia de combate ao enfretamento da pandemia de COVID-19 na região norte: relato de experiência. Revista Eletrônica Acervo Saúde, 12(12), e5745. 10.25248/reas.e5745.2020. 